\title{
Ethics in Buddhist Training
}

\author{
William L. Mikulas
}

Published online: 18 December 2014

(C) Springer Science+Business Media New York 2014

\section{Introduction}

Monteiro, Musten and Compson (2014) have provided us a wonderful article summarizing some of the issues that have been discussed, formally and informally, in the Buddhist community for a number of years. Elsewhere, I have discussed some of these topics, including issues in interfacing Buddhism and Western psychology (Mikulas 2007) and significant common confusions surrounding the construct of mindfulness (Mikulas 2011). In this commentary, I discuss ethics - strategies for teaching ethics within a Buddhism program and specific issues raised by Monteiro et al. (2014).

\section{Teaching Ethics}

Here, I make some suggestions for teaching ethics, in general and within the context of a Buddhist program. These are things I have found helpful in a practical sense, not just based on theory. First is to recognize how institutionalized religion has claimed ethical teachings as a way to encourage good behavior and support the church. The primary incentive is a favorable rebirth and/or being reborn in a heaven realm. I readily acknowledge that this may be true or false, I know nothing about this. But, this is not the importance of ethics for awakening or walking a spiritual path such as Buddhism. This distinction catches people's attention, particularly those burned out or disillusioned by church-based ethical teachings.

For people on a spiritual path, ethical behavior facilitates awakening and reduces suffering. Buddhist precepts are "protectors" to help one live a good, peaceful, and loving life. An

W. L. Mikulas $(\bowtie)$

Department of Psychology, University of West Florida, 11000

University Parkway, Pensacola, FL 32514-5750, USA

e-mail: benitamikulas@cox.net awakened person or advanced practitioner does not become so "good" that he or she resists unethical behavior. Rather, for such a person, ethical behavior is effortless and spontaneous. Thus, acting ethically is a way to facilitate awakening.

Meditation and mental training are readily impaired by the results of unethical behavior and by the poisons that motivate unethical behavior (e.g., greed, aversion, delusion). An angry episode with a co-worker can easily keep a person from later finding a peaceful mind in meditation. Buddhaghosa (1975) divided his classic fifth century Visuddhimagga into three sections: virtue (sila), concentration (samadhi), and understanding (prajna). All three influence each other. It is a useful exercise to come up with examples of all six causal effects.

In reviewing treatments for substance abuse, Bayles (2014, p. 23) suggested that Buddhist precepts "are similar to a harm reduction program, and when coupled with mindfulness, they can become relapse prevention tools." And Aitken (1984, p. 15) pointed out how in Zen, "Comments on the precepts by Bodhidharma and Dogen Zenji are studied as koans."

Many people when hearing or reading a list of Buddhist precepts or the Eightfold Path wearily respond, "Yeah, yeah, I try to do most of that." Then, their interest moves on. What is critical here is to flesh out the depth, breadth, and widespread implications of these ethical teachings (e.g., Aitken 1984). Following are some examples.

Avoiding killing can be related to include aggression/ hatred in the mind and developing respect for all life (cf. Native American Indians and Native Hawaiians). Stealing can be understood to include stealing ideas and wasting another person's time. Lying can result in guilt and fear and often leads to additional lying to cover up the first lying. On the other hand, always being truthful simplifies life and improves relations with others.

Right thought can be discussed relative to cognitive behavior therapy and when thoughts lead to other behaviors and when thoughts are the result of other behaviors. The 
Dhammapada begins: "All experience is preceded by mind, led by mind, and made by mind. Speak or act with a corrupted mind and suffering follows...speak or act with a peaceful mind and happiness follows" (Fronsdal 2008, p. 3).

Right speech includes no lying, vanity, or gossip. It should be constructive and helpful. A provocative conversation topic is how this relates to texting and social media. A good exercise is to try to practice right speech for a week as follows: For everything said or about to be said, ask yourself "Is this true? Is it kind? Is it necessary?" The "necessary" question is particularly subtle and revealing, often exposing self-based dynamics and attachments.

In a cognitive/Buddhist treatment program for addictive and HIV risk behavior, Avants and Margolin (2004) included training in ethics. This includes learning to avoid "addict speech" (e.g., lying, manipulation), "addict behavior" (e.g., needle sharing, irresponsible sexual behavior), and "addict livelihood" (e.g., dealing, prostitution).

Finally, I have found that people respond strongly to the Buddhist understanding that karma is based on intention, not overt behavior. Thus, the same superficially same behavior can be done with wholesome or unwholesome intent. The same basic behavior can be done mindfully or not, compassionately or not, and in a way that increases or decreases suffering.

Of course, in covering the whole Buddhist path, ethical behavior occurs throughout, not just in the precepts and Eightfold Path. For example, it is found in the causes and results of clinging and grasping the poisons of the mind, dependent origination, and the Brahmaviharas.

\section{Right Mindfulness}

Each part of the Eightfold Path begins with the same word (sammā in Pali, samyak in Sanskrit). This is usually translated as "right". Words that better capture the original sense include "perfect", "wholeness", and "completeness".

Monteiro et al. suggested that an action is "right" if it leads to the alleviation of suffering. This is certainly true in part, but a similar argument could be for "right" leading to insight (prajna) and/or awakening. From my perspective, what constitutes right mindfulness could vary considerably between people, possibly including the right balance of concentration and awareness, the right attitude, or the right object of mindfulness.

Currently, many theorists and practitioners are concerned about the effects of pulling one part of the Buddhist path out of the context of the other parts. The argument is that the complete package is what is most effective and just a piece by itself is not "right". Monteiro et al. suggested that right mindfulness requires other aspects of the path, such as right view and right action. From their point of view, right mindfulness requires ethics.

What I think is important here is to have a clear distinction between mindfulness and right mindfulness, however, those are defined. That is, we want to be clear on exactly what mindfulness is and how to optimally cultivate its components. Then, we can move to right mindfulness and explore how mindfulness can be individualized and embedded in a broader program.

Although Monteiro et al. and others argue that training right mindfulness requires training in the other parts of the Buddhist path, particularly ethics, the converse is not necessarily true. That is, it may be that one can learn Buddhistbased ethical principles independent of other aspects of Buddhist practice. For example, Boorstein (1985) discussed the use of right speech as a therapeutic technique in conjunction with traditional psychotherapy. Here, right speech is taught outside the Buddhist context.

\section{Whom Not to Teach}

If teaching mindfulness to an individual or group results in increased suffering or delusions, then this teaching is probably not ethical and probably not "right mindfulness". Monteiro et al. discuss some of the common concerns here, particularly as they relate to corporations and the military. If the goals of a corporation or a military group are considered antithetical to Buddhist ethics, is it ethical to help them better in achieving their goals? If a corporation uses what they call mindfulness training to make workers more accepting of questionable management practices, is this ethical or "right mindfulness"? Olendzki (2014, p. 30) pointed out that many corporate tycoons are interested in mindfulness training for their workers "as long as it makes employees more accepting about what they are required to do and does not raise troublesome ethical questions."

In their discussion of these issues, Monteiro et al. touch on some of the vast complexities involved in real life examples: Life is "seldom neat and actions rarely clear in their virtue or lack thereof." Training the military may help them "respond appropriately in morally ambiguous conditions." And mindfulness training of workers might lead to positive changes in the corporation. Let us expand on these.

Currently, mindfulness is very popular in the business world, with continually more examples from small family businesses to large corporations. Reports tell of increased worker happiness, health, and productivity. There are three major problems with this literature. First, the vast majority of the examples are not part of the academic literature, since they are done for business reasons, not research. They are reported in the popular press and trade magazines. Second is that it is not clear which of these mindfulness programs are really 
mindfulness, as we might define it. This lack of clarity is due to inadequate reporting of details, the lack of any agreed-upon professional or lay definition of mindfulness, and the cultural tendency to call all sorts of things mindfulness, because of mindfulness' current popularity. The third problem is that this literature does not show that mindfulness is better than alternatives. Before mindfulness became popular, businesses were discovering the value of breaks for yoga and/or meditation, with reports of similar results as is now said of mindfulness. So, it will be a while before we can make strong conclusions about mindfulness and businesses.

In their discussion of mindfulness training in corporations, Monteiro et al. are concerned that a misunderstanding of nonjudgmental awareness may result in workers being taught to be more pliable, more passive and accepting of corporate unethical actions, and more tolerant of oppression by management. Here is where I am in a very small minority. I understand the history and politics that led to North American approaches and definitions of mindfulness as requiring nonjudgmental awareness and acceptance. But I think this is very wrong and problematical, as I have argued elsewhere (e.g., Mikulas 2011). As I understand and teach mindfulness, it involves a pure awareness, which includes awareness of accepting or non-accepting, judging/categorizing or not. This awareness is not shackled by acceptance.

Thus, if I were to teach my understanding of "right mindfulness" to corporate workers, it would not lead to passive acceptance. If anything, I would expect the opposite. Workers would learn to be more aware of their feelings, thoughts, and actions as related to internal and external cues. They would develop a clearer perception of their interfacing with the corporation, which might lead to constructive ways of improving the corporation, including becoming more ethical. Thus, in most cases, I would be predisposed to teach mindfulness to corporation workers, even if I had some reservations about the practices and goals of the corporation. I generally think that one of the best things we can do to help our species is to help people learn how to quiet their minds, increase awareness, open their hearts, and reduce attachments.

The most popular military and law enforcement example is the training of snipers. Should we teach people how to be more effective killers? Superficially, the fast answer is no. But what if mindfulness training made the snipers less distracted and with clearer perception. This might result in fewer mistaken kills and fewer civilian casualties. Refusing to teach mindfulness to this group will not reduce the number of snipers and may increase deaths.

Also, if mindfulness training increases compassion, then the snipers might do less killing. But this could go too far.
Olendzki (2014, p. 30) described the case of a policeman who quit his job following mindfulness meditation "because he realized that now he would hesitate to shoot if he had to draw his weapon. This was a threat to his fellow officers; he knew, so he resigned." So, should we only do mindfulness training up to a point, so the military people are more aware and compassionate, but not to the point wherein they are impaired or quit their jobs? If so, should we further limit mindfulness training given to those who already are somewhat aware and compassionate? Of course, there are no simple answers to such somewhat silly questions.

I have a friend who is high in the military and trained to make significant decisions relative to international military actions. I think it is good for him and our country that he studies mindfulness and other aspects of the Buddhist path. I am concerned about some of his peers, many of whom are motivated by ego-based attachments that can lead to unethical behavior and unnecessary suffering.

In summary, I am very optimistic about how mindfulness, ethics, and other parts of the Buddhist path can help individuals and cultures. I appreciate Monteiro et al. making us more aware of some of the ethical issues in this enterprise. And I especially appreciate the distinction between "mindfulness" and "right mindfulness".

\section{References}

Aitken, R. (1984). The mind of clover: Essays in Zen Buddhist ethics. San Francisco: North Point Press.

Avants, S. K., \& Margolin, A. (2004). Development of spiritual selfschema (3-S) therapy for the treatment of addictive and HIV risk behavior: a convergence of cognitive and Buddhist psychology. Journal of Psychotherapy Integration, 14, 253-289.

Bayles, C. (2014). Using mindfulness in a harm reduction approach to substance abuse treatment: a literature review. International Journal of Behavioral Consultation and Therapy, 9(2), 22-25.

Boorstein, S. (1985). Notes on right speech as a psychotherapeutic technique. Journal of Transpersonal Psychology, 17, 47-56.

Buddhaghosa, B. (1975). The path of purification (Visuddhimagga). Kandy: Buddhist Publication Society.

Fronsdal, G. (2008). The Dhammapada. Boston: Shambhala.

Mikulas, W. L. (2007). Buddhism and Western psychology: fundamentals of integration. Journal of Consciousness Studies, 14(4), 4-19.

Mikulas, W. L. (2011). Mindfulness: significant common confusions. Mindfulness, 2, 1-7.

Monteiro, L. J., Musten, R. F., \& Compson, J. (2014). Traditional and contemporary mindfulness: finding the middle path in the tangle of concerns. Mindfulness, 6, 1-13.

Olendzki, A. (2014). The mindfulness wedge. Tricycle, 24(1), 30-31. 